\title{
ANTIMICROBIAL AND MODULATION EFFECTS OF SELECTED GHANAIAN MEDICINAL PLANTS
}

\author{
E. Ekuadzi ${ }^{1 *}$, R. A. Dickson ${ }^{1}$, T. C. Fleischer ${ }^{2}$, S. O. Dapaah ${ }^{3}$, E. O. Reynolds ${ }^{1}$, \\ E. S. Akpabey ${ }^{1}$ and M. G. Fianu ${ }^{1}$ \\ ${ }^{1}$ Department of Pharmacognosy, \\ ${ }^{2}$ Department of Herbal Medicine, \\ ${ }^{3}$ Department of Pharmaceutics, \\ Faculty of Pharmacy and Pharmaceutical Sciences, KNUST, Kumasi \\ *Corresponding author: eekuadzi.pharm@knust.edu.gh
}

\begin{abstract}
The alarming rise in the incidences of multidrug-resistant microorganisms and the decline in new antibiotic discovery make the search for new antimicrobial agents or efforts at restoring the activity of older antibiotics to which the microbes have developed resistance very necessary. The aim of the present study is to investigate the antimicrobial and modulation effects of the 70\% ethanol extracts of Lannea schimperi, Commelina nudiflora and Piliostigma reticulatum against susceptible strains of microorganisms. Using the broth microdilution method, the minimum inhibitory concentrations (MICs) of the extracts were determined. The checkerboard assay was used to determine the modulation effects when sub-inhibitory concentrations of plant extracts were combined with the standard antibiotics. All three plants extracts possessed weak antimicrobial effects. For the modulation experiments, fifteen of the twenty-seven combinatorial cases yielded biologically significant effects. The ethanol extracts of the three plants studied here are good modulators as they reduced the MIC of ciprofloxacin and ketoconazole by factors that are comparable to that of reserpine. However the exact compounds and their exact mechanism of modulation require further investigation.
\end{abstract}

Keywords: Anti-infective, modulation, Lannea schimperi, Commelina nudiflora, Piliostigma reticulatum, ethnomedicine

\section{INTRODUCTION}

Antimicrobial agents since their introduction have greatly reduced illness and death from infectious diseases. However in the last few decades, the spread of new diseases, the reemergence of diseases thought of as under control, the alarming trend of antimicrobial resis- tance and the decline in new antibiotic discovery make the search for new antimicrobial agents necessary. The risk of increased economic and social costs and death make antimicrobial resistance a threat to global public health. If allowed to spread, this phenomenon would undermine infectious disease control and 


\section{$2 \quad$ Ekuadzi et al.}

reverse the gains made so far (WHO, 2014).

Multidrug-resistant (MDR) microorganisms, namely, methicillin-resistant Staphylococcus aureus, vancomycin resistant enterococci, extended-spectrum cephalosporin-resistant Escherichia coli and Klebsiella species and MDR Pseudomonas aeruginosa most frequently cause life-threatening diseases in humans (Giske et al., 2008; Talbot et al., 2006). The current reports of resistance, means that treatment for severe infections, for which these organisms are implicated, may need to be initiated with different treatment options. The challenge though is that fewer treatment options are available and are costly for people living in low -income countries. To restore the activity of cheaper antibiotics that MDR bacteria have made inactive, research has been devoted to finding new agents from natural sources that can modulate bacterial resistance (Kovač et al., 2015). An agent is said to possess a modulatory effect on an antibiotic if it is able to reduce its MIC by certain factors (Dickson et al., 2006).

Medicinal plants serve as potential sources of anti-infective and resistance modifying agents. Commelina nudiflora L. (Commelinaceae), Lannea schimperi (Hochst. Ex A. Rich.) Engl. (Anacardiaceae) and Piliostigma reticulatum (DC) Hochst. (leguminosae) are medicinal plants which find use in traditional medicine in the treatment and management of infectious diseases (Contributors, 2015 and Kisangau et al., 2007). Previous studies on P. reticulatum has shown antimicrobial (Awe and Omojasola, 2009; Babajide, et al., 2008; Zerbo et al., 2013) and trypanocidal (Atawodi et al., 2004) activities. C. nudiflora has also been shown to exhibit antimicrobial activities (Kuppusamy et al., 2015). In addition, L. schimperi has been shown to possess antibacterial (Haule et al., 2012) and antifungal (Kisangau et al., 2009) activities.

These plants are being investigated here for their antimicrobial and resistance modulation effects using antibiotic-susceptible strains of microorganisms.

\section{METHODS}

\section{Plant collection and authentication}

The stem bark of Piliostigma reticulatum and the fresh leaves of Commelina nudiflora were collected from the Kwame Nkrumah University of Science and Technology (KNUST) Botanical garden. The stem bark of Lannea schimperi was collected from Kwahu Asakraka in the Eastern region. All three plants were collected in August 2014. Botanical identities were confirmed at the Department of Herbal Medicine herbarium, KNUST. Voucher specimen of $C$. nudiflora (KNUST/HM1/2015/L009), $L$. schimperi (KNUST/HM1/2015/S006) and $P$. reticulatum (KNUST/HM1/2015/S032) have been deposited in the same department.

\section{Microorganisms used}

Nine microorganisms, including four Grampositive bacteria (Enterococcus faecalis ATCC 29212, Streptococcus pyogenes clinical strain, Staphylococcus aureus ATCC 25923 and $\mathrm{Ba}$ cillus subtilis NCTC 10073), four Gramnegative bacteria (Salmonella typhi NCTC 6017, Escherichia coli NCTC 9002, Pseudomonas aeruginosa ATCC 27853 and Klebsiella pneumonia clinical strain) and one fungi (Candida albicans clinical strain) were used for the antimicrobial and modulation tests.

\section{Extraction of plant materials}

Fifty grams of the air-dried plant materials were soxhlet extracted using $500 \mathrm{ml}$ of $70 \%$ ethanol for $12 \mathrm{~h}$. The resulting extracts were reduced to dryness on a rotary evaporator. The percentage yields for the L. schimperi, $C$. nudiflora and $P$. reticulatum were 5.53, 6.20 and $5.70 \% \mathrm{w} / \mathrm{w}$ respectively. A $20 \mathrm{mg} / \mathrm{mL}$ stock solution was prepared by dissolving $0.1 \mathrm{~g}$ of the exthanolic extracts in $5 \mathrm{ml}$ of DMSO.

\section{Phytochemical screening}

The presence of phenolics, saponins, steroids, reducing sugars, flavonoids, alkaloids and triterpenes were detected using simple qualitative phytochemical methods (Evans, 2009). 
Antimicrobial and modulation assays

Minimal inhibitory concentrations (MICs) of the plant extracts and the standard drugs (ciprofloxacin and ketoconazole) were determined using the micro-well broth dilution methods. Six dilutions were made from the stock solution of the plant extracts by two-fold serial dilutions in sterile distilled water. The resultant concentrations in the wells were between $9.09 \mathrm{mg} / \mathrm{ml}$ and $0.14 \mathrm{mg} / \mathrm{ml}$. Inoculums of microorganisms were prepared from $12 \mathrm{~h}$ broth cultures and serial dilutions were made to achieve a suspension of approximately $10^{5}$ $\mathrm{CFU} / \mathrm{ml}$.

The wells were prepared by dispensing $100 \mu 1$ of double strength nutrient broth and $100 \mu \mathrm{L}$ each of the test samples together with $20 \mu \mathrm{l}$ of the inoculum. After $24 \mathrm{~h}$ incubation at $37^{\circ} \mathrm{C}$, optical densities in each well were read using the Synergy HT microplate reader (Bio-Tek Instruments, USA), at $600 \mathrm{~nm}$. Percentage growth was calculated according to the following equation:

$\%$ Growth $=\left[\left(\mathrm{OD}_{600}\right.\right.$ of wells containing drug / $\mathrm{OD}_{600}$ of drug-free well) $\left.\times 100\right]$

after the subtraction of ODs of microorganismfree well.

Modulation of antimicrobial resistance was evaluated using the same method, except that the medium was supplemented with subinhibitory concentrations $(200 \mu \mathrm{g} / \mathrm{mL})$ of the extracts for the determination of the MICs of ciprofloxacin and ketoconazole. Reserpine at a concentration of $10 \mu \mathrm{g} / \mathrm{mL}$ served as positive control.

The extract modulation factors (MF) were used to evaluate the antimicrobial effects of the extracts on the MIC of the antibiotic.

$\mathrm{MF}=(\mathrm{MIC}$ antibiotic / MIC antibiotic + modulator)

A modulation factor $>2$ was set as the cut-off for biologically significant modulation Gröbla- cher et al., 2012).

The fractional inhibitory concentration index (FICI) was used to evaluate the effect of the combination of antibacterial agents

FICI = FIC (standard drug) + FIC (extract).. (3)

FIC $($ standard drug) = MIC (standard drug in the presence of extract) / MIC (standard drug only)

FIC $($ extract $)=$ MIC $($ extract in the presence of standard drug)/ MIC (extract only)....

(Synergy: FICI $\leq 0.5$, additive: FICI $=0.5-$ 1.0, indifference: FICI $=1-2$, antagonism: FICI $\geq 2$ ) (Gröblacher et al., 2012).

\section{RESULTS AND DISCUSSION}

The $70 \%$ ethanol extracts of the three medicinal plants studied showed weak antimicrobial activities against the tested microorganisms (Table 1). The least MIC of $0.28 \mathrm{mg} / \mathrm{mL}$ was shown by $C$. nudiflora extract against $E$. coli. The highest MIC of $8.37 \mathrm{mg} / \mathrm{mL}$ was registered by $L$. schimperi extract against the same microorganism. Of the three medicinal plants involved in this study, the extract of $C$. nudiflora was the best with MIC values ranging between 0.28 and $1.39 \mathrm{mg} / \mathrm{mL}$. The antimicrobial effects reported here are consistent with similar studies conducted by other workers (Awe and Omojasola, 2009; Babajide et al., 2008; Kisangau et al., 2009; Kuppusamy et al., 2015; Zerbo et al., 2013). Furthermore, the three medicinal plants were investigated for their modulation effects.

Fifteen of the 27 combinatorial cases yielded biologically significant modulation factors causing more than twofold reduction of the MIC of the standard drugs, ciprofloxacin and ketoconazole (Table 2). The highest modulation factor of 70 fold reduction in the MIC of ciprofloxacin was by $C$. nudiflora against $P$. aeruginosa. 

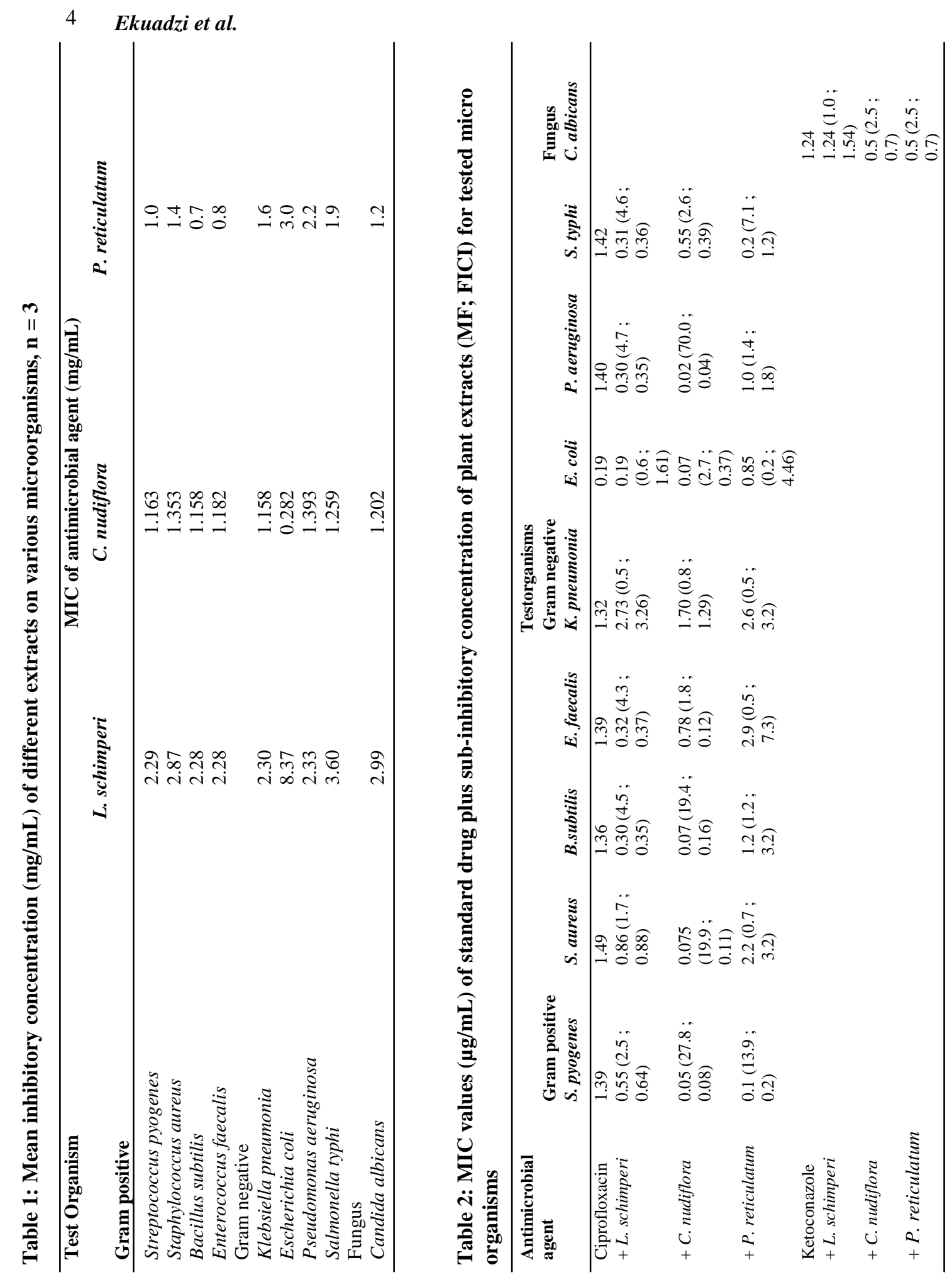

Journal of Science and Technology @ KNUST December 2016 
In the modulation assays against the antibiotic susceptible strains, synergistic and additive interactions were found in 13 and 3 of the 27 combinatorial cases respectively (Table 2). These were mainly seen with the extracts of $C$. nudiflora and L. schimperi. Five combinatorial cases were indifferent and six were antagonistic. The extract of $P$. reticulatum showed antagonistic and indifferent effects when it was combined with ciprofloxacin against the bacteria strains. However, in combination with ketoconazole, it showed additive effect against $C$. albicans.

The results reported in the present study reveal that the selected medicinal plants bear weak antimicrobial effects. They however demonstrate immense modulation effects in combination with standard antibiotics. These effects observed in the plant extracts may be due to any one or more of the secondary metabolites contained in them (Table 3). Although their exact mechanism of action is not known, we postulate that the synergistic and additive effects observed may be due to the initial damage of the microbial cell wall lipid layer by these secondary metabolites (Trombetta et al., 2005).

This subsequently increases the permeability of the membrane of the microbes and subsequent leakage of intracellular materials. Furthermore, it may increase the accumulation of the antibiotics into the cell and interacting with sites that are critical for antibacterial effects.

\section{CONCLUSIONS}

Altogether the present study revealed that the $70 \%$ ethanol extracts of L. schimperi, C. nudiflora and $P$. reticulatum have weak antimicrobial effects. However, they are good modulators, as they reduced the MIC of ciprofloxacin and ketoconazole by factors that are comparable to those of reserpine, a known modulator. These findings have not been previously reported and these medicinal plants represent potential sources of antibacterial resistance modifying agents. However, the exact compounds and their mechanisms of modulation require further investigation.

\section{ACKNOWLEDGEMENTS}

The authors greatly appreciate Mr. Clifford Kofi Asare, a local herbalist who collected the plant materials. We also acknowledge the technical support of Mr. Francis Amankwah of the Department of Pharmaceutics, KNUST.

\section{REFERENCES}

Atawodi, S., Bulus, T., Ibrahim, S., Ameh, D., Nok, A., Mamman, M. and Galadima, M. (2004). In vitro trypanocidal effect of methanolic extract of some nigerian savannah plants. African Journal of Biotechnology, 2 (9): $317-321$.

Awe, S. and Omojasola, P. (2009). A compara-

Table 3: Phytochemical constituents present in the plant extracts

\begin{tabular}{llll}
\hline Secondary metabolites & L..schimperi & C. nudiflora & P. reticulatum \\
\hline Phenolics & - & + & + \\
Saponins & + & + & + \\
Steroids & + & + & - \\
Reducing sugars & + & + & + \\
Flavonoids & + & + & + \\
Alkaloids & + & - & + \\
Triterpenes & + & + & + \\
\hline
\end{tabular}

Key: + means indicated compounds are present, - means indicated compounds are absent 
tive study of the antibacterial activity of piliostigma reticulatum bark extract with some antibiotics. Ethnobotanical Leaflets, (9): 1118.

Babajide, O. J., Babajide, O. O., Daramola, A. O. and Mabusela, W. T. (2008). Flavonols and an oxychromonol from piliostigma reticulatum. Phytochemistry, 69(11): 22452250 .

Contributors, P. (2015). Piliostigma reticulatum (prota) Retrieved 15 July 2015 05:51 UTC, 2015, from http://uses.plantnet-project.org/e/ index.php?title $=$ Piliostigma_reticulatum_ (PROTA)\&oldid=196866

Dickson, R., Houghton, P., Hylands, P. and Gibbons, S. (2006). Antimicrobial, resistance -modifying effects, antioxidant and free radical scavenging activities of mezoneuron benthamianum baill., securinega virosa roxb. \&wlld. and microglossa pyrifolia lam. Phytotherapy Research, 20(1): 41-45.

Evans, W. C. (2009). Trease and evans' pharmacognosy: Elsevier Health Sciences.

Giske, C. G., Monnet, D. L., Cars, O. and Carmeli, Y. (2008). Clinical and economic impact of common multidrug-resistant gramnegative bacilli. Antimicrobial agents and chemotherapy, 52(3): 813-821.

Gröblacher, B., Kunert, O. and Bucar, F. (2012). Compounds of alpinia katsumadai as potential efflux inhibitors in mycobacterium smegmatis. Bioorganic \& medicinal chemistry, 20-(8): 2701-2706.

Haule, E. E., Moshi, M. J., Nondo, R. S., Mwangomo, D. T. and Mahunnah, R. L. (2012). A study of antimicrobial activity, acute toxicity and cytoprotective effect of a polyherbal extract in a rat ethanol-hcl gastric ulcer model. BMC Research notes, 5(1): 546551.
Kisangau, D. P., Hosea, K. M., Lyaruu, H. V., Joseph, C. C., Mbwambo, Z. H., Masimba, and P. J., Sewald, N. (2009). Screening of traditionally used tanzanian medicinal plants for antifungal activity. Pharmaceutical Biology, 47(8): 708-716.

Kisangau, D. P., Lyaruu, H. V., Hosea, K. M., and Joseph, C. C. (2007). Use of traditional medicines in the management of hiv/aids opportunistic infections in tanzania: A case in the bukoba rural district. Journal of Ethnobiology and Ethnomedicine, 3: 29-36.

Kovač, J., Šimunović, K., Wu, Z., Klančnik, A., Bucar, F., Zhang, Q. and Možina, S. S. (2015). Antibiotic resistance modulation and modes of action of (-)- $\alpha$-pinene in campylobacter jejuni. PLOS ONE, 10(4): 1-14.

Kuppusamy, P., Yusoff, M. M., Parine, N. R. and Govindan, N. (2015). Evaluation of invitro antioxidant and antibacterial properties of commelina nudiflora 1. Extracts prepared by different polar solvents. Saudi Journal of Biological Sciences, 22(3): 293-301. doi: http://dx.doi.org/10.1016/j.sjbs.2014.09.016

Talbot, G. H., Bradley, J., Edwards, J. E., Gilbert, D., Scheld, M. and Bartlett, J. G. (2006). Bad bugs need drugs: An update on the development pipeline from the antimicrobial availability task force of the infectious diseases society of America. Clinical infectious diseases, 42(5): 657-668.

Trombetta, D., Castelli, F., Sarpietro, M. G., Venuti, V., Cristani, M., Daniele, C. and Bisignano, G. (2005). Mechanisms of antibacterial action of three monoterpenes. $A n$ timicrobial agents and chemotherapy, 49(6): 2474-2478.

WHO. (2014). Antimicrobial resistance: Global report on surveillance: World Health Organization.

Zerbo, A., Koudou, J., Ouédraogo, N., 
Antimicrobial and modulation effect of selected Ghanaian medicinal plants... 7

Ouédraogo, R. and Guissou, I. P. (2013). tracts African Journal of Biotechnology, 9 Antioxidant and antibacterial activities of (33): 5407-5411.

piliostigma reticulatum (dc.) hochst ex- 